\title{
Risk factors for foot ulceration in adults with end-stage renal disease on dialysis: study protocol for a prospective observational cohort study
}

\author{
Michelle R. Kaminski ${ }^{1,2^{*}}$, Anita Raspovic ${ }^{1}$, Lawrence P. McMahon ${ }^{3}$, Bircan Erbas ${ }^{4}$ and Karl B. Landorf ${ }^{1}$
}

\begin{abstract}
Background: Adults with end-stage renal disease treated with dialysis experience a high burden of foot ulceration and lower extremity amputation. However, the risk factors for foot ulceration in the dialysis population are incompletely understood due to the lack of high-quality prospective evidence. This article outlines the design of a prospective observational cohort study, which aims to investigate the risk factors for foot ulceration in adults on dialysis.

Methods/Design: This study will recruit 430 participants with end-stage renal disease on dialysis from satellite and home-therapy dialysis units across multiple health organisations in Melbourne, Victoria, Australia. Data collection at baseline will include a participant interview, medical record review, completion of a health-status questionnaire and a non-invasive foot assessment. Twenty participants will also be recruited to a reliability study to evaluate the reproducibility of testing procedures. Primary outcome data includes: new foot ulcer(s). Secondary outcome data includes: number of new foot ulcers, time to onset of new foot ulcer(s), new lower extremity amputation(s), episodes of infection of the foot or lower extremity, episodes of osteomyelitis, foot-related hospitalisations, revascularisation procedure(s) of the lower extremity, new podiatry interventions, kidney transplantation, and mortality. Participants will be assessed at baseline, and at 12 months they will be evaluated for the primary and secondary outcomes. Multivariate Cox proportional hazards models will be used to assess predictors of new foot ulceration and time to event secondary outcomes. Logistic regression will be used for binary outcomes including prevalence of foot ulcerations.

Discussion: This is the first multi-centre prospective observational cohort study to investigate risk factors for foot ulceration in adults with end-stage renal disease on dialysis. This study will improve on prior studies by using prospective methods, multi-centre recruitment, statistical methods to control for confounding variables, and a pre-specified sample size estimation. The findings can inform the design of future trials evaluating the effectiveness of clinical interventions, which may lead to improved patient outcomes in the dialysis setting.
\end{abstract}

Keywords: Kidney failure, Chronic, Dialysis, Foot ulcer, Risk factors, Prospective studies

\section{Background}

End-stage renal disease (ESRD) is a global public health problem characterised by a significant loss in kidney function, causing retention of metabolic waste products, salt and fluid in the body [1]. The accumulation of these waste products can become fatal unless renal replacement therapy (i.e. dialysis or kidney transplantation) is sought. It is

\footnotetext{
* Correspondence: mrkaminski@students.latrobe.edu.au

'Discipline of Podiatry and Lower Extremity and Gait Studies Program, School of Allied Health, La Trobe University, Melbourne, VIC 3086, Australia ${ }^{2}$ Department of Podiatry, Eastern Health, Melbourne, VIC 3156, Australia Full list of author information is available at the end of the article
}

estimated that there are more than 1.4 million people receiving renal replacement therapy worldwide [2], with the ESRD incidence rate increasing at an annual growth rate of $8 \%$ [3].

Adults with ESRD on dialysis are at high risk for foot ulceration and subsequent lower extremity amputation [4-12]. This risk is similar to those with diabetes [5, 12, 13]. Not surprisingly, individuals who are both diabetic and dialysis-dependent have even higher rates of foot ulceration and amputation $[5,14]$. Foot ulceration is a major public health concern and can have a detrimental impact on an individual's general health, functional status and 
health-related quality of life [15-17]. Chronic foot ulcers progress to other serious lower extremity complications such as deep infections, and result in subsequent hospitalisation, limb loss, and foot-related mortality $[5,7,18,19]$. In addition, the treatment and management of foot ulcers generates a considerable financial burden with increased demand on health care systems [20-22]. For example, a recent study [23] conducted in the United States reported the annual cost of diabetic foot ulceration on public and private payers is between US $\$ 9$ - $\$ 13$ billion, not including the costs associated with diabetes management itself.

The incidence of foot ulceration in the dialysis population is currently uncertain. However, a recent retrospective study by Lavery et al. [14] estimated a cumulative foot ulceration incidence rate of 210 per 1000 person-years in dialysis patients with coexisting diabetes. The central determinants for the development of foot ulcers in the dialysis setting are poorly understood, although meta-analyses performed in our recent systematic review found that possible risk factors include: previous foot ulceration or lower extremity amputation, peripheral arterial disease, coronary artery disease, diabetes mellitus (increasing with longer duration of disease), peripheral neuropathy, retinopathy, lower serum albumin levels and higher serum phosphorus levels [24].

Risk factors reported in the literature are frequently based on associations identified in retrospective or crosssectional studies. To our knowledge, there are no adequately powered multi-centre prospective cohort studies that have investigated risk factors for foot ulceration in the dialysis population. Prospective studies are essential to gain greater control over data collection methods and provide a temporal sequence of events; that is, whether a variable is associated with an increase in the condition of interest [25].

With the above in mind, the aim of this article is to describe the design of a multi-centre prospective observational cohort study that will investigate risk factors for foot ulceration in adults with ESRD on dialysis.

\section{Methods/Design}

\section{Ethical approval}

The Human Research and Ethics Committees of La Trobe University, Eastern Health, Austin Health, and Monash Health (reference numbers: FHEC13/213, LR14/1314, LN $\mathrm{R} / 14 /$ Austin/97 and 14419X, respectively) have approved the study and all participants will provide written informed consent prior to enrolment and data collection.

\section{Study design}

The design is a multi-centre prospective observational cohort study with a 12 month follow-up period. Initially, we performed a systematic synthesis of existing literature to quantify the major risk factors for foot ulceration and amputation in adults with ESRD treated with dialysis [24]. Our decision on which risk factors to include in this prospective observational cohort study is based not only on our systematic review findings [24], but is also informed by a comprehensive review of the diabetes literature. A 12-month follow-up period was chosen as it will provide an adequate time frame for the development of new foot ulceration [26, 27].

Data collection will consist of two appointments; a baseline appointment and a follow-up appointment. One examiner (M.R.K.) will conduct the baseline and followup appointments on all participants. Figure 1 outlines the study design. Data to be collected at baseline will be obtained from an interview with the participant, medical record review, completion of a health-status questionnaire and a non-invasive foot assessment. A comprehensive literature review was performed to determine the most valid and reliable tools to measure suspected risk factors, for use in the foot assessment. The data collection form for the baseline data is available in Additional file 1 . In addition, twenty participants will also be recruited to a reliability study to assess the repeatability of the foot assessment tools. These participants will be screened for suspected risk factors for foot ulceration on two separate occasions by the same examiner (M.R.K.), with each assessment spaced one week apart. The foot assessments to be repeated on the twenty participants in the reliability study (i.e. one week later) includes: protective sensation with the Baily Instruments Ltd $^{\bullet}$ (Salford Quays, UK) Semmes-Weinstein 5.07/10 g Monofilament, vibration perception threshold with the Horwell $^{\circ}$ (Wilford, Nottingham, UK) Neurothesiometer, toe-brachial pressure index with the SysToe (Atys Medical, Soucieu-enJarrest, France) system, ankle-brachial index using the Doppler ultrasound technique and first metatarsophalangeal joint range of motion with a goniometer. One examiner (M.R.K.) will perform all of the foot assessments on the participants, thus ensuring consistency and accuracy in the measurements, and reducing the chance of systematic error.

Primary and secondary outcome data will be collected at the 12 month follow-up appointment. The data collection form for the prospective data (i.e. 12month follow-up) is available in Additional file 2 . Primary outcome data includes: new foot ulcer(s) (including new and reoccurring ulcers). Secondary outcome data includes: number of new foot ulcers, time to onset of new foot ulcer(s), new lower extremity amputation(s) (including level of amputation and reason for amputation), episodes of infection of the foot or lower extremity (including type of infection), episodes of osteomyelitis, foot-related hospitalisations (including reason for admission, length of stay, and foot-related treatments/procedures received during 


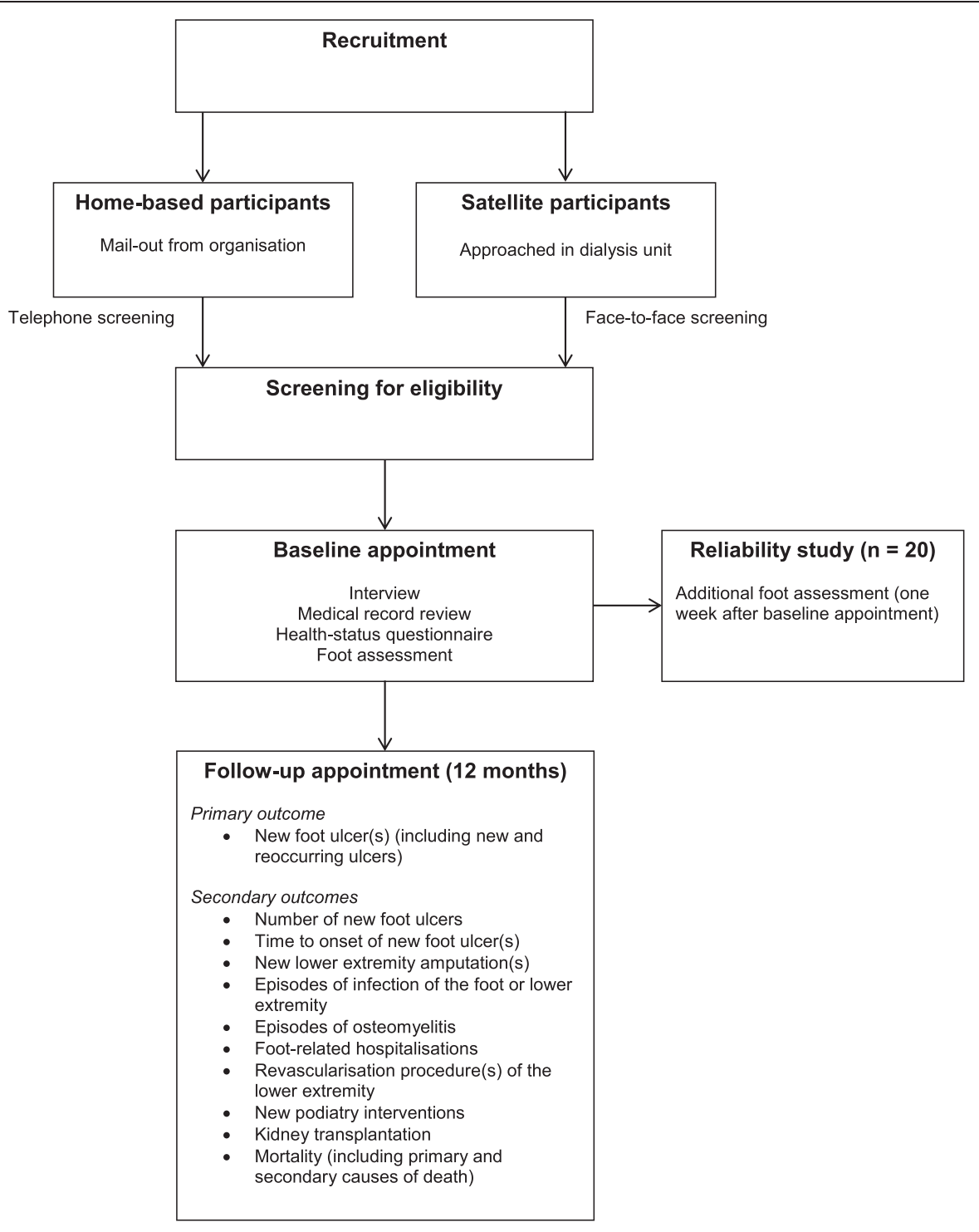

Fig. 1 Design of study

hospital admission), revascularisation procedure(s) of the lower extremity (including type of revascularisation procedure), new podiatry interventions (e.g. nail/ callus reduction, prescription of foot orthoses), kidney transplantation, and mortality (including primary and secondary causes of death).

\section{Participant recruitment, screening and eligibility criteria}

Participants will be recruited from satellite dialysis units (i.e. centres where patients attend for dialysis treatment) and home-therapy dialysis units (i.e. dialysis treatment is performed at home) throughout Eastern Health, Austin Health and Monash Health in Melbourne, Victoria, Australia. Recruitment and collection of baseline data is anticipated to occur between January 2014 and December 2014.

Prospective participants will be identified by liaising with the renal dialysis nurses in the satellite and hometherapy dialysis units, according to the study eligibility criteria. Those attending the satellite dialysis units will be screened face-to-face, whereas respondents to the mailout (i.e. home-therapy participants) will be screened for eligibility via telephone.

Patients attending for dialysis in the satellite units will be approached by the chief investigator (M.R.K.) during their dialysis treatment. If interested, they will be offered verbal and written information about the project and will have the opportunity to join the study at the time of 
meeting the researcher, or will be offered a follow-up telephone call. Alternatively, prospective participants may contact the research team at their own convenience if they are interested in participating.

Patients in the home-therapy dialysis program will be mailed a covering letter and an information package, along with an invitation to contact the research team by telephone or email if they are interested in participating. Patient lists from the home-therapy dialysis unit will be screened prior to mailing to confirm that addresses are current and to exclude any recent deaths or discharges.

To be included in the study, participants will be eligible if they:

(i) have ESRD and are clinically stable on dialysis (haemodialysis or peritoneal dialysis);

(ii) are at least 18 years of age and;

(iii) are cognitively aware (i.e. they can provide informed consent).

Participants will be excluded if they:

(i) have insufficient English skills to provide informed consent or follow instructions during the project and;

(ii) are unwilling to give informed consent to participate.

Participants' cognition and English language proficiency (to provide informed consent or follow instructions during the project) will be confirmed by the chief investigator (M.R.K.) in collaboration with the nursing staff in the dialysis units. To determine this, prospective recruits' understanding of what participation in the study involves will be ascertained prior to signing informed consent.

\section{Baseline appointment}

Data will be collected at the baseline appointment via an interview with the participant and by reviewing medical records and routine blood test results. Baseline variables or factors relating to participant characteristics, comorbidities and laboratory blood test results (Table 1) were selected based on the findings of our systematic review [24] and from a comprehensive review of the diabetes literature. An average of the three latest blood test results (i.e. C-reactive protein, serum albumin, total calcium, serum phosphate, parathyroid hormone, glycated haemoglobin and haemoglobin) will be obtained at baseline for the purposes of statistical analysis.

Previous studies have demonstrated that healthrelated quality of life is negatively impacted by the presence of a diabetic foot ulcer $[28,29]$. Generic health status will be assessed with the short-form 36 version 2.0 health survey $\left(\mathrm{SF}-36 \mathrm{v} 2^{\circ}\right)$. The SF-36v2 ${ }^{\circ}$ has been extensively validated (construct, concurrent, content, criterion and predictive validity) and provides a reliable measure of physical and mental health in a range of populations [30-33]. The SF-36v2 $2^{\circ}$ is a 36 question survey that covers eight health domains that are summarised under two components, (i) a physical component summary including: physical functioning, role-physical, bodily pain and general health, and (ii) a mental component summary including: vitality, social functioning, role-emotional and mental health [34].

A non-invasive foot assessment will screen for the suspected risk factors for foot ulceration. Neurological (Table 2), arterial (Table 3), biomechanical (Table 4), footwear (Table 5) and dermatological (Table 6) assessments will be conducted. Data will also be collected on previous history of lower extremity complications (Table 7) and foot health care behaviours, including podiatry attendance (Table 8).

\section{Neurological assessment}

The presence of peripheral neuropathy will be assessed using a Baily Instruments Ltd $^{\circ}$ (Salford Quays, UK) Semmes-Weinstein 5.07/10 g Monofilament and a Horwell ${ }^{\circ}$ (Wilford, Nottingham, UK) Neurothesiometer, based on the recommendations of the American Diabetes Association [35]. These tests will evaluate loss of protective sensation and vibration perception threshold, respectively.

A recent systematic review reported that a failed Semmes-Weinstein monofilament test is a significant and independent predictor for subsequent foot ulceration in patients with diabetes [36]. A systematic review of validation studies found that testing of loss of protective sensation with a $10 \mathrm{~g}$ monofilament has reported sensitivity of 57 to $93 \%$ and specificity of 75 to $100 \%$ for detecting diabetic neuropathy [36]. The Baily Instruments $\mathrm{Ltd}^{\circ}$ monofilament was selected for use in this study as it is one of the most accurate monofilaments to produce a $10 \mathrm{~g}$ buckling force $(100 \%$ buckling within $\pm 1.0 \mathrm{~g}$ of $10 \mathrm{~g}$ ) [37]. The plantar aspects of the hallux, first and fifth metatarsals will be assessed [38, 39].

The vibration perception threshold will be evaluated as it can identify those with less severe forms of neuropathy (i.e. before loss of protective sensation is evident clinically) [40]. A review of validation studies found that testing of vibration perception threshold with either a Neurothesiometer or Biothesiometer has reported sensitivity (77 to $100 \%$ ) and specificity (73 to $81 \%$ ) ranges for detecting diabetic neuropathy [40]. A vibration perception threshold of $>25 \mathrm{~V}$ (tested on the apex of the hallux) in at least one foot will be used as the cut off value in this study, as it has been associated with a high cumulative risk of neuropathic ulceration [41, 42]. 
Table 1 Baseline data: participant characteristics, comorbidities and laboratory blood test results

\begin{tabular}{|c|c|c|}
\hline Participants characteristics & Comorbidities & $\begin{array}{l}\text { Laboratory blood } \\
\text { test results }\end{array}$ \\
\hline Age (years) & Diabetes (documented diagnosis in medical history, including type and duration) & $\begin{array}{l}\text { C-reactive protein } \\
(\mathrm{mg} / \mathrm{L})\end{array}$ \\
\hline Sex (male or female) & Retinopathy (documented diagnosis in medical history) & $\begin{array}{l}\text { Serum albumin } \\
(\mathrm{g} / \mathrm{dL})\end{array}$ \\
\hline Height $(\mathrm{m})$ & Known peripheral neuropathy (documented diagnosis in medical history) & $\begin{array}{l}\text { Total calcium } \\
(\mathrm{mmol} / \mathrm{L})\end{array}$ \\
\hline \multirow[t]{4}{*}{ Weight (kg) } & \multirow{4}{*}{$\begin{array}{l}\text { Known peripheral arterial disease or history of lower extremity revascularisation } \\
\text { procedure (documented diagnosis in medical history or documented lower extremity } \\
\text { revascularisation procedure e.g. angioplasty) }\end{array}$} & $\begin{array}{l}\text { Serum phosphate } \\
\text { (mmol/L) }\end{array}$ \\
\hline & & $\begin{array}{l}\text { Parathyroid hormone } \\
\text { (pmol/L) }\end{array}$ \\
\hline & & $\begin{array}{l}\text { Glycated } \\
\text { haemoglobin (\%) }\end{array}$ \\
\hline & & Haemoglobin (g/L) \\
\hline Body mass index $\left(\mathrm{kg} / \mathrm{m}^{2}\right)$ & $\begin{array}{l}\text { Hypertension (documented diagnosis in medical history and must be requiring } \\
\text { medication) }\end{array}$ & \\
\hline Smoking history (past, current, never) & Dyslipidaemia (documented diagnosis in medical history) & \\
\hline Living arrangements (living alone) & \multirow{3}{*}{$\begin{array}{l}\text { Ischaemic heart disease (documented diagnosis of ischaemic heart disease, angina, } \\
\text { myocardial infarction or coronary bypass surgery in medical history) }\end{array}$} & \\
\hline Ethnicity & & \\
\hline $\begin{array}{l}\text { - Indigenous Australian (Aboriginal or } \\
\text { Torres Strait Islander) }\end{array}$ & & \\
\hline • English & \multirow[t]{3}{*}{ Congestive cardiac failure (documented diagnosis in medical history) } & \\
\hline • European & & \\
\hline - American & & \\
\hline - African & \multirow{5}{*}{$\begin{array}{l}\text { Cerebrovascular disease (documented diagnosis of cerebrovascular accident } \\
\text { or transient ischaemic attack in medical history) }\end{array}$} & \\
\hline - Asian & & \\
\hline - Pacific Islander & & \\
\hline - Other & & \\
\hline Cause of end-stage renal disease & & \\
\hline - Diabetic nephropathy & \multirow[t]{2}{*}{ Osteoarthritis (documented diagnosis in medical history) } & \\
\hline • Hypertensive nephropathy & & \\
\hline -Chronic glomerulonephritis & \multirow{5}{*}{$\begin{array}{l}\text { Inflammatory arthritis (documented diagnosis in medical history of a type of } \\
\text { inflammatory arthritis e.g. gout, rheumatoid arthritis, psoriatic arthropathy) }\end{array}$} & \\
\hline - Polycystic kidney disease & & \\
\hline • Reflux nephropathy & & \\
\hline - Renovascular disease & & \\
\hline -Vasculitis & & \\
\hline •Unknown & \multirow[t]{7}{*}{ Other (any other documented medical conditions) } & \\
\hline • Other & & \\
\hline Dialysis treatment & & \\
\hline • Haemodialysis & & \\
\hline $\begin{array}{l}\text { - Continuous ambulatory peritoneal } \\
\text { dialysis }\end{array}$ & & \\
\hline - Automated peritoneal dialysis & & \\
\hline Duration of dialysis (months) & & \\
\hline
\end{tabular}

An average of the three latest blood test results (i.e. C-reactive protein, serum albumin, total calcium, serum phosphate, parathyroid hormone, glycated haemoglobin and haemoglobin) will be obtained at baseline 
Table 2 Baseline data: neurological assessment

\begin{tabular}{|c|c|c|c|}
\hline $\begin{array}{l}\text { Neurological } \\
\text { assessments }\end{array}$ & Equipment & Procedure & Diagnosis/study definition \\
\hline $\begin{array}{l}\text { Known } \\
\text { peripheral } \\
\text { neuropathy }\end{array}$ & N/A & Medical record review. & $\begin{array}{l}\text { History of peripheral neuropathy documented in } \\
\text { medical records. }\end{array}$ \\
\hline \multirow[t]{8}{*}{$\begin{array}{l}\text { Loss of } \\
\text { protective } \\
\text { sensation }\end{array}$} & \multirow[t]{8}{*}{$\begin{array}{l}\text { Baily Instruments Ltd }{ }^{\oplus} \text { (Salford } \\
\text { Quays, UK) Semmes-Weinstein } \\
5.07 / 10 \mathrm{~g} \text { monofilament [37]. }\end{array}$} & $\begin{array}{l}\text { - Monofilament is first applied to participant's } \\
\text { hand or elbow (so that the participant knows } \\
\text { what sensation to expect) }\end{array}$ & \multirow{8}{*}{$\begin{array}{l}\text { Failure to detect the monofilament at a specific } \\
\text { site, even after re-testing the deficit site, in at } \\
\text { least one foot will result in a failed test (i.e. score } \\
\text { of }<3 / 3 \text { on either foot) [36]. }\end{array}$} \\
\hline & & - Ensure the participant's eyes are closed & \\
\hline & & $\begin{array}{l}\text { - Monofilament applied perpendicular to the skin } \\
\text { and held for } 1-2 \text { secs, applying sufficient force } \\
\text { to bend or buckle the monofilament fibre [16] }\end{array}$ & \\
\hline & & $\begin{array}{l}\text { - Monofilament applied to the plantar aspects of } \\
\text { the hallux, first metatarsophalangeal joint and fifth } \\
\text { metatarsophalangeal joint of both feet }[36,43]\end{array}$ & \\
\hline & & $\begin{array}{l}\text { - Participant is asked by the assessor to respond } \\
\text { "yes" when they feel the monofilament }\end{array}$ & \\
\hline & & $\begin{array}{l}\text { - This is repeated for all } 3 \text { sites on each foot ( } 6 \\
\text { sites in total) }\end{array}$ & \\
\hline & & - Deficit sites will be re-tested once & \\
\hline & & $\begin{array}{l}\text { - A monofilament will be not be used on more } \\
\text { than } 10 \text { participants, without a recovery period } \\
\text { of } 24 \text { hrs }[16,37,91]\end{array}$ & \\
\hline \multirow[t]{5}{*}{$\begin{array}{l}\text { Vibration } \\
\text { perception } \\
\text { threshold }\end{array}$} & \multirow[t]{5}{*}{$\begin{array}{l}\text { Horwell }{ }^{\oplus} \text { Neurothesiometer } \\
\text { (Wilford, Nottingham, UK). }\end{array}$} & $\begin{array}{l}\text { - Neurothesiometer is first applied to the } \\
\text { participant's hand or elbow (so that the } \\
\text { participant knows what sensation to expect) }\end{array}$ & \multirow[t]{5}{*}{$\begin{array}{l}\text { Vibration perception threshold }>25 \mathrm{~V} \text { in at least } \\
\text { one foot will result in a failed test [40-43]. }\end{array}$} \\
\hline & & $\begin{array}{l}\text { - Participant is asked to close their eyes and to } \\
\text { report "yes" when they first start to feel a } \\
\text { vibratory sensation }\end{array}$ & \\
\hline & & $\begin{array}{l}\text { - Neurothesiometer is applied to the apex of the } \\
\text { hallux and the voltage is gradually increased } \\
\text { until the participant perceives the vibratory } \\
\text { sensation }[40,43]\end{array}$ & \\
\hline & & $\begin{array}{l}\text { - The minimum reading at which the vibratory } \\
\text { sensation is perceived will be recorded (this is } \\
\text { repeated } 3 \text { times and an average score is } \\
\text { recorded for both feet) }[40,43]\end{array}$ & \\
\hline & & $\begin{array}{l}\text { Note: Vibration perception threshold will be } \\
\text { measured at the base of the first, third or fifth } \\
\text { metatarsals if there are current ulcers on the } \\
\text { hallux, or previous amputation of the hallux [43]. }\end{array}$ & \\
\hline
\end{tabular}

Peripheral neuropathy will be recorded if any of the following are present:

- Documentation of known peripheral neuropathy in the medical records;

- Monofilament score of $<3 / 3$ (either foot) [36];

- Vibration perception threshold $>25 \mathrm{~V}$ (either foot) [40-43].

\section{Arterial assessment}

The presence of peripheral arterial disease will be assessed by palpating pedal pulses (i.e. dorsalis pedis and posterior tibial) and by calculating the toe-brachial pressure index and the ankle-brachial pressure index bilaterally. Symptoms for peripheral arterial disease (i.e. intermittent claudication and rest pain) will not be assessed in this study, as it is likely that there is a high prevalence of asymptomatic peripheral arterial disease in this population, due to a high co-prevalence of diabetes, infections and neuropathy [44]. A combination of the toe-brachial pressure index and ankle-brachial pressure index measurements will allow for a more accurate representation of the prevalence of peripheral arterial disease, due to the known high prevalence rates of medial arterial calcification in dialysis patients $[45,46]$.

As per the recommendations of Leskinen et al. [45], toebrachial pressure indices $\leq 0.6$ and/or ankle-brachial pressure indices $\leq 0.9$ will indicate the presence of peripheral 
Table 3 Baseline data: arterial assessment

\begin{tabular}{llll}
\hline Arterial assessments & Equipment & Procedure & Diagnosis/study definition \\
\hline $\begin{array}{l}\text { Known peripheral arterial } \\
\text { disease and/or history of }\end{array}$ & N/A & Medical record review. & History of peripheral arterial disease and/or lower \\
lower extremity & & extremity revascularisation procedure documented \\
revascularisation procedure & & in medical records.
\end{tabular}

revascularisation procedure

Pedal pulses

N/A

Toe-brachial pressure index
SysToe ${ }^{\circledR}$ (Atys Medical, Soucieu-enJarrest, France).
Ankle-brachial pressure index
- Physical palpation of the dorsalis pedis and posterior tibial pulses on both feet with the examiners fingers (4 pulses in total) [52]

- Pedal pulses will be recorded as 'present' or 'absent'

- Toe pressure measurement will be performed prior to the ankle pressure measurement to ensure arterial supply to the toes is not affected

- Room temperature (minimum 21-23 $\pm 1^{\circ}$ C) to prevent vasoconstriction of digital arteries [92]

- Participants will be rested for a minimum of $15 \mathrm{~min}$ prior to assessment

- Participants to avoid use of tobacco and consumption of coffee for at least one hour prior to assessment $[92,93]$

- Pneumatic cuff $(120 \times 25 \mathrm{~mm})$ is placed on the proximal phalanx of hallux (i.e. proximal cuff) $[47,48]$

Note: If hallux is absent, a $90 \times 15 \mathrm{~mm}$ digital cuff will be used on the second toe $[48,49]$.

- Double-sided tape is applied to sensor [47]

- Sensor is positioned on the plantar aspect of the hallux (or second toe) and secured with another pneumatic cuff (i.e. distal cuff) $[47,48]$

- Turning the SysToe ${ }^{\circledast}$ device on will cause an automated sequence involving inflation of the distal cuff, then inflation of the proximal cuff, followed by rapid deflation of the distal cuff and slower deflation of the proximal cuff $\left(3 \mathrm{~mm} \mathrm{Hg} \mathrm{s}^{-1}\right)[47,48]$

- The return of blood perfusion (measured by the proximal cuff) will be recorded as the toe systolic pressure $[47,48]$

- Toe pressure assessment is repeated for contralateral side (if appropriate)

- Toe-brachial pressure index value is calculated by dividing the toe systolic pressure by the highest (or available) brachial systolic pressure

- Toe brachial pressure index value calculated separately for left and right lower limbs

Note: Brachial systolic pressures obtained in the ankle-brachial pressure index assessment will be used to calculate the toe-brachial pressure index value.

- Room temperature (minimum $21-23 \pm 1^{\circ} \mathrm{C}$ ) to prevent vasoconstriction of digital arteries [92]
Absence of $\geq 2$ pedal pulses will indicate peripheral arterial disease [52]

Toe-brachial pressure index $\leq 0.6$ will indicate peripheral arterial disease $[44,45,53]$.
Hadeco Bidop

ES100V3 Bi-

Directional Doppler

Complete with LCD
Ankle-brachial pressure index $\leq 0.9$ will indicate peripheral arterial disease $[44,45,53,54]$. 
Table 3 Baseline data: arterial assessment (Continued)

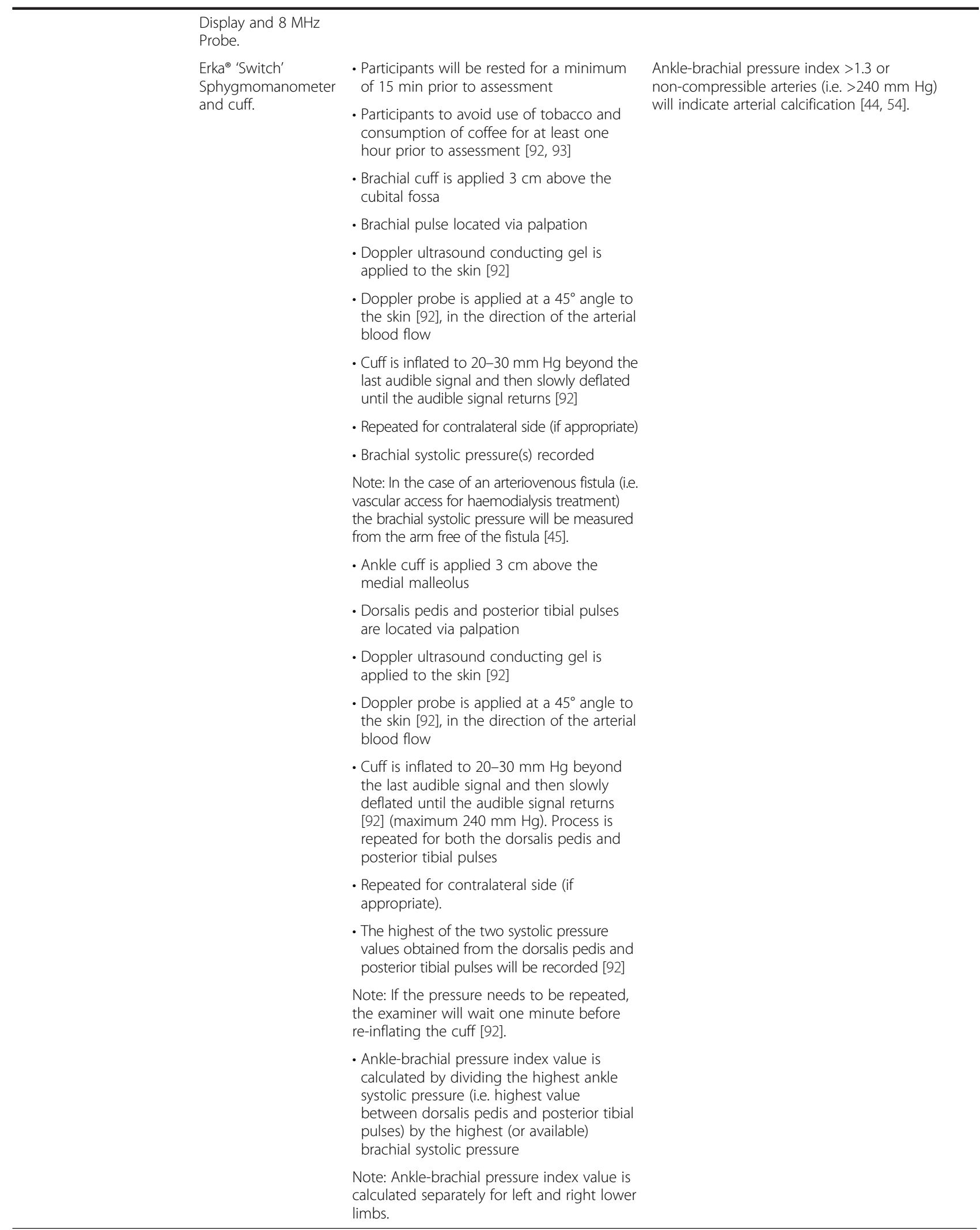


Table 4 Baseline data: biomechanical assessment

\begin{tabular}{|c|c|c|c|}
\hline Biomechanical assessments & Equipment & Procedure & Diagnosis/study definition \\
\hline \multirow[t]{3}{*}{ Foot deformity } & \multirow[t]{3}{*}{ The Manchester Scale [57]. } & $\begin{array}{l}\text { - The presence of hammer/claw toes, } \\
\text { hallux abducto valgus, bony } \\
\text { prominences (e.g. prominent metatarsal } \\
\text { heads), Charcot neuroarthropathy and } \\
\text { any other foot deformities (e.g. forefoot } \\
\text { pad atrophy) will be assessed visually [57] }\end{array}$ & \multirow[t]{3}{*}{$\begin{array}{l}\text { Foot deformity will be recorded } \\
\text { with the presence of } \geq 1 \text { foot } \\
\text { deformity on either foot. }\end{array}$} \\
\hline & & $\begin{array}{l}\text { - Hallux abducto valgus will be graded in } \\
\text { accordance with the Manchester Scale } \\
\text { (no deformity }=1 \text {, mild deformity }=2 \text {, } \\
\text { moderate deformity =3, severe } \\
\text { deformity }=4 \text { ) }[57,58]\end{array}$ & \\
\hline & & $\begin{array}{l}\text { - Foot deformity will be recorded as } \\
\text { 'present' or 'absent' }\end{array}$ & \\
\hline $\begin{array}{l}\text { Range of motion } \\
\text { ( } 1^{\text {st }} \text { metatarsophalangeal joint) }\end{array}$ & Goniometer. & $\begin{array}{l}\text { - Passive range of dorsiflexion at the } 1^{\text {st }} \\
\text { metatarsophalangeal joint will be } \\
\text { measured using goniometry with the } \\
\text { 'static non-weightbearing technique } 1^{\text {' }} \\
\text { described by Hopson et al. [60] }\end{array}$ & $\begin{array}{l}\text { Range of motion }<65^{\circ} \text { indicates } \\
\text { limited joint mobility of the first } \\
\text { metatarsophalangeal joint }[60] .\end{array}$ \\
\hline \multirow[t]{5}{*}{ Plantar pressures } & $\begin{array}{l}\text { Tekscan Matscan }{ }^{\circledast} \text { system } \\
\text { (Tekscan Inc, South Boston, MA, USA). }\end{array}$ & $\begin{array}{l}\text { - Plantar pressures will be assessed } \\
\text { during level barefoot walking with the } \\
\text { Tekscan Matscan }{ }^{\circledR} \text { system }[64,94]\end{array}$ & \multirow{5}{*}{$\begin{array}{l}\text { Mean peak plantar pressures } \\
\text { will be investigated to } \\
\text { determine whether they are } \\
\text { predictive of foot ulceration. }\end{array}$} \\
\hline & $\begin{array}{l}5.7 \mathrm{~mm} \text { thick floor mat }(436 \times 369 \mathrm{~mm}) \text {, } \\
2288 \text { resistive sensors }\left(1.4 \text { sensors } / \mathrm{cm}^{2}\right) \text {, } \\
\text { dynamic events captured with scan } \\
\text { rates of } 440 \mathrm{~Hz} \text {. }\end{array}$ & $\begin{array}{l}\text { - The two-step gait initiation protocol } \\
\text { will be used, with the technique as } \\
\text { described by Zammit et al. [64], except } \\
\text { that both feet will be assessed }\end{array}$ & \\
\hline & \multirow[t]{3}{*}{$\begin{array}{l}\text { FootMat }^{\mathrm{TM}} 7.0 \text { software (Tekscan Inc, } \\
\text { South Boston, MA, USA). }\end{array}$} & $\begin{array}{l}\text { - The mat will be calibrated for each } \\
\text { patient using that patient's own weight } \\
\text { before each testing session }\end{array}$ & \\
\hline & & $\begin{array}{l}\text { - Peak plantar pressure will be measured } \\
\text { at seven regions of the foot, including } \\
\text { the heel, midfoot, first } \\
\text { metatarsophalangeal joint, second } \\
\text { metatarsophalangeal joint, 3-5 } \\
\text { metatarsophalangeal joints, hallux and } \\
\text { lesser toes [64] }\end{array}$ & \\
\hline & & $\begin{array}{l}\text { - The mean peak plantar pressure values } \\
\text { of the three trials of each foot will be } \\
\text { used for final data analysis }[64,95]\end{array}$ & \\
\hline
\end{tabular}

arterial disease. The Sys'Toe ${ }^{\bullet}$ (Atys Medical, Soucieuen-Jarrest, France) system was chosen to determine the toe systolic pressure as it has been shown to be a valid and reliable clinical assessment tool (Intraclass Correlation Coefficients, ICC $=0.89$ and 0.91 for the right and left sides respectively) [47-49]. The Doppler ultrasound technique will be used to assess the ankle and brachial systolic pressures, as it is known to be a valid and reliable assessment method in the detection of peripheral arterial disease $[50,51]$. In addition, ankle- brachial pressure indices $\leq 0.9$ have been reported to have a high sensitivity (75 \%) and specificity (86\%) for the diagnosis of peripheral arterial disease in pooled meta-analyses [50].

Peripheral arterial disease will be recorded if any of the following are present:

- Documentation of known peripheral arterial disease in the medical records and/or history of lower extremity revascularisation procedure;

Table 5 Baseline data: footwear assessment

\begin{tabular}{lll}
\hline $\begin{array}{l}\text { Footwear } \\
\text { assessments }\end{array}$ & Procedure & Diagnosis/study definition \\
\hline $\begin{array}{l}\text { Fit, general } \\
\text { features, style and } \\
\text { condition }\end{array}$ & $\begin{array}{l}\text { - The fit (length, width, depth), general features (fixation, forefoot sole } \\
\text { flexion point, heel height, materials), style and condition of footwear } \\
\text { will be assessed based on the footwear assessment tool described by }\end{array}$ & $\begin{array}{l}\text { Footwear will be deemed inappropriate if there are } \\
\text { condition. }\end{array}$ \\
\hline
\end{tabular}


Table 6 Baseline data: dermatological assessment

\begin{tabular}{|c|c|c|}
\hline $\begin{array}{l}\text { Dermatological } \\
\text { assessments }\end{array}$ & Procedure & Diagnosis/study definition \\
\hline \multirow[t]{3}{*}{ Skin pathology } & $\begin{array}{l}\text { - The presence of hyperkeratosis (callus), heloma dura (corns), uraemic pruritus, } \\
\text { xerosis, calciphylaxis and other skin pathologies will be assessed visually }[18,66 \text {, } \\
67,70-72]\end{array}$ & \multirow[t]{3}{*}{$\begin{array}{l}\text { Skin pathology will be recorded with the } \\
\text { presence of } \geq 1 \text { skin pathology on either foot. }\end{array}$} \\
\hline & $\begin{array}{l}\text { - Severity of xerosis will be graded in accordance with the Xerosis Severity Scale } \\
\text { (mild }=1-2 \text {, moderate }=3-4 \text {, severe }=5-6)[66,67]\end{array}$ & \\
\hline & - Skin pathology will be recorded as 'present' or 'absent' & \\
\hline \multirow[t]{2}{*}{ Nail pathology } & $\begin{array}{l}\text { - The presence of half-and-half nail, absent lunula, onychomycosis, onychocrypto- } \\
\text { sis (ingrown nail), onychauxis (thickened nail) and other nail pathologies will be } \\
\text { assessed visually }[70,71]\end{array}$ & \multirow[t]{2}{*}{$\begin{array}{l}\text { Nail pathology will be recorded with the } \\
\text { presence of } \geq 1 \text { nail pathology on either foot. }\end{array}$} \\
\hline & - Nail pathology will be recorded as 'present' or 'absent' & \\
\hline
\end{tabular}

- Absence of $\geq 2$ pedal pulses after palpating the dorsalis pedis and posterior tibial pulses on both feet [52];

- Toe-brachial pressure index $\leq 0.6$ (either foot) $[44,45,53]$ and/or ankle-brachial pressure index $\leq 0.9$ (either foot/lower extremity) [44, 45, 50, 53, 54].

Arterial calcification will be recorded if any of the following are present:

- Ankle-brachial pressure index $>1.3$ (either foot/ lower extremity) [44, 54];

- Non-compressible peripheral arteries (i.e. systolic pressure $>240 \mathrm{~mm} \mathrm{Hg}$ ).

\section{Biomechanical assessment}

Anomalies of foot structure have been found to be predictive of foot ulceration in prospective studies [41, 55, 56]. The grading of hallux valgus will be evaluated using the Manchester Scale [57], as it provides a valid representation of the degree of hallux valgus deformity [58]. Intra- and inter-rater reliability have been found to be excellent, with kappa (к) values of 0.77 and 0.86 , respectively [57]. Foot deformity will be recorded if any of the following are present:

Table 7 Baseline data: history of lower extremity complications

\begin{tabular}{ll}
$\begin{array}{l}\text { Lower } \\
\text { extremity } \\
\text { complication }\end{array}$ & Procedure \\
\hline Foot ulceration & $\begin{array}{l}\text { - Past or current foot ulcers will be determined by } \\
\text { self-report, observation and medical record review } \\
\text { - The location, type and duration of a current foot } \\
\text { ulcer will be recorded }\end{array}$ \\
& $\begin{array}{ll}\text { Lower } \\
\text { extremity }\end{array}$ \\
amputation & by self-report, observation and medical record review \\
& - Lower extremity amputations will be classified as \\
& minor (below ankle) or major (above ankle)
\end{tabular}

- Hallux abducto valgus (graded in accordance with the Manchester Scale) [35, 57];

- Hammer/claw toes [35];

- Bony prominences (e.g. prominent metatarsal heads);

- Charcot neuroarthropathy [35];

- Other (e.g. forefoot pad atrophy).

Limited joint range of motion (e.g. first metatarsophalangeal joint) has also been associated with an increased risk of foot ulceration in prospective and case-control studies [55, 56, 59].

Dorsiflexion range of motion of the first metatarsophalangeal joint will be assessed in accordance with the 'static non-weightbearing technique 1' described by Hopson et al. [60]. This technique has been shown to be a reliable clinical measurement $(\mathrm{ICC}=0.95)$. Limited range of motion at the first metatarsophalangeal joint will be documented if:

- Passive, non-weightbearing dorsiflexion is $<65^{\circ}$ (either foot) [60].

Elevated peak plantar pressures have been found to be a statistically significant predictor of diabetic foot ulceration 
Table 8 Baseline data: foot health care behaviours and podiatry attendance

\begin{tabular}{|c|c|c|}
\hline $\begin{array}{l}\text { Foot health care behaviours and } \\
\text { podiatry attendance }\end{array}$ & Procedure & Diagnosis/study definition \\
\hline \multirow[t]{7}{*}{ Foot health care behaviours } & $\begin{array}{l}\text { - Foot health care behaviours will be investigated via } \\
\text { participant interview }\end{array}$ & \multirow[t]{7}{*}{$\begin{array}{l}\text { Foot health care behaviours will be considered 'poor } \\
\text { if the participant answers "no" to } \geq 3 \text { questions. }\end{array}$} \\
\hline & $\begin{array}{l}\text { - Participants will be asked to respond "yes" or "no" to the } \\
\text { following questions: }\end{array}$ & \\
\hline & (i) Do you inspect your feet daily? & \\
\hline & (ii) Do you avoid walking barefoot? & \\
\hline & (iii) Are you able to reach your feet? & \\
\hline & (iv) Do you treat your own nails and skin lesions? & \\
\hline & (v) Have you ever seen a podiatrist before? & \\
\hline \multirow[t]{2}{*}{ Podiatry attendance } & $\begin{array}{l}\text { - Podiatry attendance will be investigated via participant } \\
\text { interview }\end{array}$ & \multirow[t]{2}{*}{$\begin{array}{l}\text { Podiatry attendance will be recorded as the number } \\
\text { of visits per year. }\end{array}$} \\
\hline & $\begin{array}{l}\text { - Participants will be asked: How many times have you } \\
\text { seen a podiatrist in the last } 12 \text { months? }\end{array}$ & \\
\hline
\end{tabular}

in prospective studies [61-63]. Peak plantar pressures will be assessed during level barefoot walking using a two-step gait initiation protocol [64] with the Tekscan Matscan ${ }^{\circledR}$ system (Tekscan Inc, South Boston, MA, USA). Peak plantar pressures will be measured at seven regions of the foot, including the heel, midfoot, first metatarsophalangeal joint, second metatarsophalangeal joint, third to fifth metatarsophalangeal joints, hallux, and lesser toes [64]. The mean peak plantar pressure values of the three trials (of each foot) will be used for the purposes of analysis.

\section{Footwear assessment}

Minor trauma that results in tissue damage or a break in the cutaneous barrier of the skin is most commonly due to ill-fitting or inappropriate footwear, which is frequently implicated in the development of foot ulcers due to rubbing and repetitive trauma $[41,55]$. Reiber et al. [55] found that a minor traumatic event was one of the main component causes for the development of foot ulcers, which was present in $77 \%$ of the foot ulcer pathways. In addition, pressure from footwear caused the minor traumatic event in $55 \%$ of the participants [55]. Assessment of footwear fit, general features, type and condition is based on the recommendations of the validated footwear assessment tool described by Barton et al. [65]. Footwear will be deemed inappropriate if any of the following are present:

- Poor shoe fit (i.e. length, width and depth);

- Inappropriate shoe style (i.e. for foot type, activity, foot problems etc.) or;

- Poor shoe condition [65].

\section{Dermatological assessment}

Skin and nail pathologies have been found to be predictive of foot ulceration in people with diabetes in prospective studies $[27,55]$. The grading of xerosis severity will be evaluated using the Xerosis Severity Scale, which has been used in several randomised trials [66-68]. Skin pathology will be recorded if any of the following are present:

- Hyperkeratosis [16, 69];

- Heloma dura [16, 69];

- Uraemic pruritus [70, 71];

- Xerosis (graded in accordance with the Xerosis Severity Scale) [67];

- Calciphylaxis [18, 72];

- Other.

Nail pathology will be recorded if any of the following are present:

- Half-and-half nail [70, 71];

- Absent lunula [70, 71];

- Onychomycosis [27, 69];

- Onychocryptosis [69];

- Onychauxis [69];

- Other.

\section{Foot health care behaviours and podiatry attendance}

Foot health care behaviours will be considered 'poor' if the participant answers "no" to three or more of the following questions:

- Do you inspect your feet daily?

- Do you avoid walking barefoot?

- Are you able to reach your feet?

- Do you treat your own nails and skin lesions? (e.g. calluses or corns)

- Have you ever seen a podiatrist before? 
Regular podiatry attendance will be determined with the following question:

- How many times have you seen a podiatrist in the last 12 months?

\section{Follow-up appointment}

The follow-up appointment will occur 12 months after the baseline appointment. Satellite participants will be followed-up face-to-face in the dialysis units, whereas home-therapy participants will be contacted via telephone. Prior to the follow-up appointment, participant medical records will be screened for any recent deaths or discharges. This is to ensure that the families of participants who died during the study are not contacted.

\section{Primary outcome}

The primary outcome in this prospective observational cohort study will be:

- new foot ulcer(s) (including new and reoccurring ulcers).

A foot ulcer will be defined as a 'full thickness skin break that is distal to the ankle joint, and may extend into or through the dermis and involve deeper structures such as bones, tendons, joint capsules and ligaments' [27, 73]. Current foot ulcers (i.e. ulcers present at baseline appointment) that healed and re-ulcerated during the follow-up period will also be recorded as new foot ulcers. At the 12month follow-up appointment, participants will selfreport whether they developed a new foot ulcer since their baseline appointment. This information will be verified by reviewing participants' medical records. All new foot ulcers documented at the follow-up appointment will be differentiated into 'new' and 'reoccurring' ulcers. All medical histories of participants will be reviewed to determine whether any new foot ulcers occurred during the 12-month follow-up period.

\section{Secondary outcomes}

Secondary outcome data will also be collected at the 12 month follow-up appointment including:

- number of new foot ulcers;

- time to onset of new foot ulcer(s);

- new lower extremity amputation(s) (including level of amputation and reason for amputation);

- episodes of infection of the foot or lower extremity (including type of infection);

- episodes of osteomyelitis;

- foot-related hospitalisations (including reason for admission, length of stay and foot-related treatments/ procedures received during hospital admission);
- revascularisation procedure(s) of the lower extremity (including type of procedure);

- new podiatry interventions (e.g. nail reduction, prescription of foot orthoses);

- kidney transplantation and;

- mortality (including primary and secondary causes of death).

All secondary outcomes will be self-reported by participants and then verified by reviewing medical records. All medical histories of participants will be reviewed to determine whether any of the secondary outcomes occurred during the 12-month follow-up period. The time to onset of new foot ulcer(s) will be defined as the 'number of days between the baseline appointment and the development of a new foot ulcer'. Medical records will be referred to for the first documented encounter of the new foot ulcer and this date will be recorded. A lower extremity amputation will be defined as a 'complete loss of any part of the lower extremity [74], including any digit, partial foot amputation or higher'. Lower extremity amputations resulting from accidental trauma unrelated to ESRD or the presence of a tumour will not be recorded. Lower extremity amputations will be classified as major or minor. A major amputation will be documented if there is loss of limb above the ankle, or minor amputation if below the ankle [74, 75]. Mortality data will also be collected at the follow-up appointment. Date of death (including primary and secondary causes of death) will also be recorded from reviewing patient medical histories. For those participants that die during the study period, hospital medical records will be reviewed to assess for the primary and secondary outcomes up until the date of death.

\section{Sample size}

Prospective sample size calculations were performed using Stata 11 Data Analysis and Statistical Software (StataCorp LP, Texas, USA) for the following predictor variables; diabetes mellitus and peripheral neuropathy. Based on these calculations, a sample of 430 participants will provide $80 \%$ power to detect a clinically worthwhile difference of $15 \%$ in the incidence of foot ulceration between those with and without diabetes. This sample size will also provide $80 \%$ power to detect a clinically worthwhile difference of $10 \%$ in the incidence of foot ulceration between those with and without peripheral neuropathy. This sample size also allows for a $20 \%$ loss to follow-up.

\section{Data handling and statistical analysis}

Data will be entered into a Microsoft Excel $^{\oplus}$ spread sheet for the development of an analytical file. A predefined 
statistical analysis plan will be established between an experienced biostatistician (B.E.) and the research team prior to commencing the analysis. Baseline sociodemographic, health-related quality of life and clinical characteristics of participants will be calculated and expressed as mean \pm standard deviation or median $\left(25^{\text {th }}\right.$ to $75^{\text {th }}$ percentile) for continuous variables and number (proportion) for categorical variables. For comparison of baseline variables between different groups (for example, foot ulcer or no foot ulcer), independent samples $t$-tests will be calculated for continuous variables and chi-square $\left(x^{2}\right)$ tests for categorical variables. Unadjusted foot ulcer incidence rates will be calculated for number of events per 1000 person-years. Multivariate Cox proportional hazards models will be used to assess predictors of new foot ulceration and time to event secondary outcomes. Logistic regression will be used for binary outcomes, such as prevalence of foot ulcerations.

Base regression models will be developed to fit each risk factor one at a time with other variables including baseline demographics and possible confounders as described in Table 9 [9, 76, 77], and statistical significance will be assessed. As a sensitivity analysis, we will also use forward selection when building models with $P$-values set at 0.1. Confounders will be retained if they change the estimated associations between risk factors and the outcome by $10 \%$ or more, or are significant at the $5 \%$ level in adjusted models [78]. After a number of iterations, all risk factors will then be combined in a multivariable regression model. Possible interactions will also be assessed. Strata specific analysis of regression models using diabetes (yes/no) and sex (male/female) will be conducted to assess variables for possible effect modification. Interaction terms will then be included in the regression models if there is evidence of an effect modification from any of these variables. Risk estimates will be presented as hazard ratios and/or odds ratios (depending on the regression model) with corresponding $95 \%$ confidence intervals (CIs). Statistical significance will be set at the conventional level of $P<0.05$.

Intra-examiner reliability of the assessor (M.R.K.) will be evaluated using ICCs for continuous data and the weighted kappa $(\kappa)$ statistic for ordinal data. To assess the strength of linear correlation between the two measurements (i.e. to detect random and systematic errors) [25], ICCs and corresponding $95 \%$ CIs of the type $(3,1)$ will be calculated for single measures and type $(3, k)$ for average measures. ICC values $>0.75$ indicate good reliability, ICCs ranging from 0.50 to 0.75 imply moderate reliability and ICCs $<0.50$ suggest poor reliability [25]. The $95 \%$ Limits of Agreement will also be calculated to examine the level of agreement between the two measurements $[25,79]$. Absolute agreement in addition to linear weighted kappa will be calculated for ordinal data to determine the proportion of the total amount of agreement between the two measurements that is not explained by chance $[80,81]$. Weighted kappa values $>0.8$ represent excellent agreement, $>0.6$ substantial levels of agreement, 0.4 to 0.6 moderate agreement and $<0.4$ poor to fair agreement [25].

Data analysis will be undertaken using IBM SPSS version 22.0 or later (IBM Corp, Somers, NY, USA), Stata 11 Data Analysis and Statistical Software (StataCorp LP, Texas, USA), QualityMetric Health Outcomes ${ }^{\text {Tm }}$ Scoring Software 4.5.1 and FootMat ${ }^{\mathrm{tm}}$ 7.0 Software (Tekscan Inc, South Boston, MA, USA).

\section{Discussion}

Foot ulceration is a major public health problem that can have a negative impact on an individual's general health, functional status and health-related quality of life [15-17]. Despite the high prevalence of foot ulceration in the dialysis population, there is a paucity of highquality prospective studies that have investigated the risk factors associated with this condition. Existing risk factor studies [5, 6, 8-10, 12, 82-88] have been limited by small sample sizes, inadequate control for confounding variables, do not encompass a full range of risk factors, and the majority are either cross-sectional or retrospective. Moreover, these study designs do not examine for a temporal sequence of events, so it is difficult to conclude whether these risk factors are associated with an increase in foot ulceration. Importantly, our study protocol has been developed to improve on the design of previous studies.

Our prospective observational cohort study has been designed to investigate the risk factors for foot ulceration in adults with ESRD on dialysis. We have chosen to evaluate the risk factors for foot ulceration specifically in dialysis patients, as these individuals have been found to be at high risk for foot complications $[7,9,89,90]$. People with or without diabetes will be recruited into the study. This cohort study will improve on prior studies by using prospective methods, multi-centre recruitment, statistical methods to control for confounding variables, and a pre-specified sample size estimation.

The study will investigate participant characteristics, medical history, blood tests, health-related quality of life and foot assessment data to assess whether any predict important clinical outcomes including: new foot ulcer(s), (primary outcome), number of new foot ulcers, time to onset of new foot ulcer(s), new lower extremity amputation(s), episodes of infection of the foot or lower extremity, episodes of osteomyelitis, foot-related hospitalisations, revascularisation procedure(s) of the lower extremity, and mortality (secondary outcomes).

There are several strengths of our study. Firstly, the baseline data collection form (Additional file 1) is based 
Table 9 Risk factors and potential confounding variables

\begin{tabular}{|c|c|}
\hline Continuous variables & Categorical variables \\
\hline Participant characteristics & Participant characteristics \\
\hline - Age & - Male sex \\
\hline - Body mass index & - Current smoker \\
\hline \multirow{2}{*}{$\begin{array}{l}\text { Health-related quality of life } \\
\left(\mathrm{SF}-36 \mathrm{~V} 2^{\circ}\right)\end{array}$} & - Living alone \\
\hline & Comorbidities \\
\hline - Physical Component Score & - Diabetes mellitus \\
\hline - Mental Component Score & - Retinopathy \\
\hline Comorbidities & - Peripheral neuropathy \\
\hline - Duration of diabetes & - Peripheral arterial disease \\
\hline \multirow{2}{*}{$\begin{array}{l}\text { Dialysis-related variables } \\
\text { - Duration of dialysis }\end{array}$} & - Arterial calcification \\
\hline & - Hypertension \\
\hline Laboratory blood tests & -Dyslipidaemia \\
\hline - C-reactive protein & - Ischaemic heart disease \\
\hline - Serum albumin & - Congestive cardiac failure \\
\hline • Total calcium & - Cerebrovascular disease \\
\hline - Serum phosphate & - Osteoarthritis \\
\hline - Parathyroid hormone & - Inflammatory arthritis \\
\hline - Glycated haemoglobin (HbA1c) & Lower extremity complications \\
\hline •Haemoglobin & - Previous foot ulceration \\
\hline \multirow{11}{*}{$\begin{array}{l}\text { Other } \\
\text { • Peak plantar pressures }\end{array}$} & - Current foot ulcer present at \\
\hline & baseline \\
\hline & $\begin{array}{l}\text { - Previous lower extremity } \\
\text { amputation }\end{array}$ \\
\hline & Other \\
\hline & $\begin{array}{l}\text { - Reduced range of motion of the } \\
1^{\text {st }} \text { metatarsophalangeal joint }\end{array}$ \\
\hline & - Foot deformity \\
\hline & - Inappropriate/ill-fitting footwear \\
\hline & - Skin pathology \\
\hline & - Nail pathology \\
\hline & - Poor foot health care behaviours \\
\hline & - Regular podiatry attendance \\
\hline
\end{tabular}

Potential confounding variables that will be considered in the regression models are boldface

on the findings of our systematic review [24] and from a comprehensive review of the diabetes literature. Secondly, one examiner (M.R.K.) will perform all of the foot assessments on the participants, thus ensuring consistency and accuracy in the measurements, and reducing the chance of systematic error. Thirdly, we will assess the reliability of the foot assessment tools. Twenty participants will be included in a reliability study, which will evaluate the reproducibility of the testing procedures. A one week test-retest interval was chosen as it is sufficient time to avoid fatigue, learning or memory effects, and will also avoid genuine changes in the measurement variables [25]. Fourthly, the study protocol has been pragmatically designed to encompass a full range of risk factors and to ensure that the findings can be generalised and applied to clinical practice (if there are significant risk factors for foot ulceration identified). Finally, a prospective sample size calculation was performed to ensure that the study is adequately powered.

There are also a few potential limitations to our study. While the examiner will avoid providing feedback and education to participants during their foot assessment, it is not possible to control for all other potential confounding treatments or interventions that participants may receive from other sources during the study period. For example, a participant may receive an intervention that directly affects their risk of developing a foot ulcer or not (e.g. prescription of pressure offloading foot orthoses). In addition, participants involved in this study may become more aware of their own foot health as a result of their participation, and may therefore change their behaviour during the study period (e.g. start to perform daily foot checks, seek podiatry treatment, etc.). Ethical considerations may also affect the final outcomes of this study. For example, the researcher will report any abnormal findings from the individual foot assessments (e.g. new foot ulcer or presence of peripheral arterial disease) to the medical teams in the dialysis units. As such, participants may receive new interventions as a result (e.g. lower extremity revascularisation procedure), which may have a direct effect on the final outcomes. Lastly, as this cohort is made up of severely ill participants, mortality and loss to follow-up due to comorbidities could be potentially higher than the expected $20 \%$. If this is exceeded, we will address this issue by using imputation techniques for missing data in regression models.

\section{Conclusion}

This is the first multi-centre prospective observational cohort study to investigate risk factors for foot ulceration in adults with ESRD treated with dialysis. In addition, we have pre-specified our sample size to ensure clinically and statistically meaningful results. The study will improve on prior studies by using prospective methods, multi-centre recruitment, statistical methods to control for confounding variables, and a pre-specified sample size estimation. The results will provide highlevel evidence, and a temporal sequence of events for risk factors contributing to the development of foot ulceration in the dialysis population. The identification of potentially modifiable risk factors can inform the design of future trials investigating the effectiveness of clinical interventions to reduce the burden of lower limb disease in adults on dialysis. 


\section{Additional files}

Additional file 1: Data collection form: Baseline data. Data collection form is designed to screen for potential risk factors for foot ulceration at baseline. (PDF $159 \mathrm{~kb}$ )

Additional file 2: Data collection form: Prospective data (12-month follow-up). Data collection form is designed to obtain primary and secondary outcome data at the 12-month follow-up. (PDF $145 \mathrm{~kb}$ )

\section{Abbreviations}

ESRD: End-stage renal disease; SF-36v2 ${ }^{\oplus}$ : Short-form 36 version 2.0 health survey; ICC: Intraclass correlation coefficient; Cl: Confidence interval; N/A: Not applicable.

\section{Competing interests}

K.B.L. is the Deputy Editor and A.R. is a member of the Editorial Board of the Journal of Foot and Ankle Research. It is journal policy that editors are removed from the peer review and editorial decision making processes for papers they have co-authored.

\section{Authors' contributions}

MRK, KBL, AR and LPM conceived the study idea and designed the protocol. All authors developed the protocol for data analysis. MRK, KBL and BE drafted the protocol manuscript. AR and LPM commented and revised the draft manuscript. All authors read and approved the final manuscript prior to submission.

\section{Acknowledgements}

M.R.K. receives an Australian National Health and Medical Research Council postgraduate scholarship (GNT1056105). The Eastern Health Podiatry Department is supplying the majority of equipment for use in the study. Consumables and some equipment have been donated by Briggate Medical Company (Victoria, Australia). The SF-36v2 ${ }^{\circledR}$ user licence and analysis software have been donated by Optum Incorporated (formally known as QualityMetric Incorporated). The FootMat ${ }^{\mathrm{TM}} 7.0$ user licence and analysis software have been donated by Tekscan (Tekscan Inc, South Boston, MA, USA). The authors would like to acknowledge Eastern Health, Austin Health, Monash Health, Briggate Medical Company, Optum Incorporated and Tekscan for their support of the project.

\section{Author details}

${ }^{1}$ Discipline of Podiatry and Lower Extremity and Gait Studies Program, School of Allied Health, La Trobe University, Melbourne, VIC 3086, Australia. ${ }^{2}$ Department of Podiatry, Eastern Health, Melbourne, VIC 3156, Australia. ${ }^{3}$ Departments of Renal Medicine and Obstetric Medicine, Eastern Health Clinical School, Monash University, Melbourne, VIC 3128, Australia. ${ }^{4}$ Department of Public Health, College of Science, Health and Engineering, School of Psychology and Public Health, La Trobe University, Melbourne, VIC 3086, Australia.

\section{Received: 21 January 2015 Accepted: 10 September 2015}

\section{Published online: 18 September 2015}

\section{References}

1. Krishnan AV, Kiernan MC. Uremic neuropathy: clinical features and new pathophysiological insights. Muscle Nerve. 2007;35:273-90.

2. Moeller S, Gioberge S, Brown G. ESRD patients in 2001: global overview of patients, treatment modalities and development trends. Nephrol Dial Transplant. 2002;17:2071-6.

3. Schieppati A, Remuzzi G. Chronic renal diseases as a public health problem: epidemiology, social, and economic implications. Kidney Int. 2005;68:57-10.

4. Eggers PW, Gohdes D, Pugh J. Nontraumatic lower extremity amputations in the Medicare end-stage renal disease population. Kidney Int. 1999;56:1524-33.

5. Kaminski M, Frescos N, Tucker S. Prevalence of risk factors for foot ulceration in patients with end-stage renal disease on haemodialysis. Intern Med J. 2012:42:e120-8.

6. Locking-Cusolito H, Harwood L, Wilson B, Burgess K, Elliot M, Gallo K, et al. Prevalence of risk factors predisposing to foot problems in patients on hemodialysis. Nephrol Nurs J. 2005;32:373-84.
7. Margolis DJ, Hofstad O, Feldman HI. Association between renal failure and foot ulcer or lower-extremity amputation in patients with diabetes. Diabetes Care. 2008;31:1331-6.

8. Ndip A, Lavery LA, Lafontaine J, Rutter MK, Vardhan A, Vileikyte L, et al. High levels of foot ulceration and amputation risk in a multiracial cohort of diabetic patients on dialysis therapy. Diabetes Care. 2010;33:878-80.

9. Ndip A, Rutter MK, Vileikyte L, Vardhan A, Asari A, Jameel M, et al. Dialysis treatment is an independent risk factor for foot ulceration in patients with diabetes and stage 4 or 5 chronic kidney disease. Diabetes Care. 2010;33:1811-6.

10. Pliakogiannis T, Bailey S, Cherukuri S, Taskapan H, Ahmad M, Oliver T, et al. Vascular complications of the lower extremities in diabetic patients on peritoneal dialysis. Clin Nephrol. 2008;69:361-7.

11. Speckman RA, Frankenfield DL, Roman SH, Eggers PW, Bedinger MR, Rocco $\mathrm{MV}$, et al. Diabetes is the strongest risk factor for lower-extremity amputation in new hemodialysis patients. Diabetes Care. 2004;27:2198-203.

12. Jones NJ, Chess J, Cawley S, Phillips AO, Riley SG. Prevalence of risk factors for foot ulceration in a general haemodialysis population. Int Wound J. 2012. doi: 10.1111/j.1742-481X.2012.01044.x

13. Hill MN, Feldman HI, Hilton SC, Holechek MJ, Ylitalo M, Benedict GW. Risk of foot complications in long-term diabetic patients with and without ESRD: A preliminary study. ANNA J. 1996;23:381-6.

14. Lavery LA, Lavery DC, Hunt NA, La Fontaine J, Ndip A, Boulton AJ. Amputations and foot-related hospitalisations disproportionately affect dialysis patients. Int Wound J. 2013. doi:10.1111/iwj.12146.

15. Boulton AJM. The diabetic foot: grand overview, epidemiology and pathogenesis. Diabetes Metab Res Rev. 2008;24 Suppl 1:S3-6.

16. Singh N, Armstrong DG, Lipsky BA. Preventing foot ulcers in patients with diabetes. JAMA. 2005:293:217-28.

17. Ragnarson Tennvall G, Apelqvist J. Health-related quality of life in patients with diabetes mellitus and foot ulcers. J Diabetes Complications. 2000;14:235-41.

18. Lewis S, Raj D, Guzman NJ. Renal failure: Implications of chronic kidney disease in the management of the diabetic foot. Semin Vasc Surg. 2012;25:82-8.

19. Valabhij J. Foot problems in patients with diabetes and chronic kidney disease. J Ren Care. 2012;38:99-108.

20. Driver VR, Fabbi M, Lavery LA, Gibbons G. The costs of diabetic foot: the economic case for the limb salvage team. J Am Podiatr Med Assoc. 2010;100:335-41.

21. Lazzarini PA, Gurr JM, Rogers JR, Schox A, Bergin SM. Diabetes foot disease: the Cinderella of Australian diabetes management? J Foot Ankle Res. 2012:5:24.

22. Boulton AJM, Vileikyte L, Ragnarson-Tennvall G, Apelqvist J. The global burden of diabetic foot disease. Lancet. 2005:366:1719-24.

23. Rice JB, Desai U, Cummings AK, Birnbaum HG, Skornicki M, Parsons NB. Burden of diabetic foot ulcers for medicare and private insurers. Diabetes Care. 2014;37:651-8.

24. Kaminski MR, Raspovic A, McMahon LP, Strippoli GFM, Palmer SC, Ruospo $\mathrm{M}$, et al. Risk factors for foot ulceration and lower extremity amputation in adults with end-stage renal disease on dialysis: a systematic review and meta-analysis. Nephrol Dial Transplant. 2015; doi:10.1093/ndt/gfv114.

25. Portney LG, Watkins MP. Foundations of clinical research: applications to practice. 3rd ed. Upper Saddle River, NJ: Pearson Education Inc; 2009.

26. Abbott CA, Vileikyte $L$, Williamson $S$, Carrington AL, Boulton AJ. Multicenter study of the incidence of and predictive risk factors for diabetic neuropathic foot ulceration. Diabetes Care. 1998;21:1071-5.

27. Boyko EJ, Ahroni JH, Cohen V, Nelson KM, Heagerty PJ. Prediction of diabetic foot ulcer occurrence using commonly available clinical information: the Seattle diabetic foot study. Diabetes Care. 2006;29:1202-7.

28. Ribu L, Birkeland K, Hanestad BR, Moum T, Rustoen T. A longitudinal study of patients with diabetes and foot ulcers and their health-related quality of life: wound healing and quality-of-life changes. J Diabetes Complications. 2008:22:400-7.

29. Ribu L, Hanestad BR, Moum T, Birkeland K, Rustoen T. Health-related quality of life among patients with diabetes and foot ulcers: association with demographic and clinical characteristics. J Diabetes Complications. 2007;21:227-36.

30. McHorney CA, Ware JE, Lu JFR, Sherbourne CD. The MOS 36-item short-form health survey (SF-36): III. Tests of data quality, scaling assumptions, and reliability across diverse patient groups. Med Care. 1994;32:40-66. 
31. MCHorney CA, Ware JE, Raczek AE. The MOS 36-item short-form health survey (SF-36): II. Psychometric and clinical tests of validity in measuring physical and mental health constructs. Med Care. 1993;31:247-63.

32. McHorney CA, Ware JE, Rogers W, Raczek AE, Lu JFR. The validity and relative precision of MOS short- and long-form health status scales and Dartmouth COOP charts. Results from the Medical Outcomes Study. Med Care. 1992;30 Suppl 5:MS253-65.

33. Ware JE, Sherbourne CD. The MOS 36-item short-form health survey (SF-36): I. Conceptual framework and item selection. Med Care. 1992;30:473-83.

34. Ware Jr JE, Kosinski M, Bjorner JB, Turner-Bowker DM, Gandek B, Maruish ME. User's manual for the SF-36v2 ${ }^{\circledR}$ health survey. 2nd ed. Lincoln, Rl: QualityMetric Incorporated; 2007.

35. Boulton AJM, Mueller MJ, Sheehan P, Wukich DK, Armstrong DG, Albert SF, et al. Comprehensive foot examination and risk assessment: A report of the task force of the foot care interest group of the American Diabetes Association, with endorsement by the American Association of Clinical Endocrinologists. Diabetes Care. 2008;31:1679-85

36. Feng Y, Schlösser FJ, Sumpio BE. The Semmes Weinstein monofilament examination as a screening tool for diabetic peripheral neuropathy. J Vasc Surg. 2009;50:675-82.

37. Booth J, Young MJ. Differences in the performance of commercially available 10-g monofilaments. Diabetes Care. 2000;23:984-8.

38. Feng Y, Schlösser FJ, Sumpio BE. The Semmes Weinstein monofilament examination is a significant predictor of the risk of foot ulceration and amputation in patients with diabetes mellitus. J Vasc Surg. 2011;53:220-6.

39. Bakker K, Apelqvist J, Schaper NC. International Working Group on Diabetic Foot Editorial Board: Practical guidelines on the management and prevention of the diabetic foot 2011. Diabetes Metab Res Rev. 2012;28:225-31.

40. Garrow AP, Boulton AJM. Vibration perception threshold - a valuable assessment of neural dysfunction in people with diabetes. Diabetes Metab Res Rev. 2006;22:411-9.

41. Abbott $\mathrm{CA}$, Johnson $\mathrm{KE}$, Ryder $\mathrm{CH}$, Torkington $\mathrm{R}$, Van Ross ERE, Whalley AM, et al. The North-West diabetes foot care study: incidence of, and risk factors for, new diabetic foot ulceration in a community-based patient cohort. Diabet Med. 2002;19:377-84.

42. Young MJ, Breddy JL, Veves A, Boulton AJM. The prediction of diabetic neuropathic foot ulceration using vibration perception thresholds. A prospective study. Diabetes Care. 1994;17:557-60.

43. Jayaprakash $P$, Bhansali A, Bhansali S, Dutta P, Anantharaman R, Shanmugasundar $G$, et al. Validation of bedside methods in evaluation of diabetic peripheral neuropathy. Indian J Med Res. 2011;133:645-9.

44. Garimella PS, Hart PD, O'Hare A, DeLoach S, Herzog CA, Hirsch AT. Peripheral artery disease and CKD: a focus on peripheral artery disease as a critical component of CKD care. Am J Kidney Dis. 2012;60:641-54.

45. Leskinen $Y$, Salenius JP, Lehtimäki T, Huhtala H, Saha H. The prevalence of peripheral arterial disease and medial arterial calcification in patients with chronic renal failure: requirements for diagnostics. Am J Kidney Dis. 2002:40:472-9.

46. Ng S-Y, Cheng S-W, Chu W-L, Lui S-L, Lo W-K. Screening by trained nurses for peripheral vascular disease in continuous ambulatory peritoneal dialysis patients with and without diabetes. Perit Dial Int. 2003;23 Suppl 2:S134-8.

47. Hoyer C, Sandermann J, Petersen LJ. Randomised diagnostic accuracy study of a fully automated portable device for diagnosing peripheral arterial disease by measuring the toe-brachial index. Eur J Vasc Endovasc Surg. 2013;45:57-64

48. Pérez-Martin A, Meyer G, Demattei C, Böge G, Laroche JP, Quéré I, et al. Validation of a fully automatic photoplethysmographic device for toe blood pressure measurement. Eur J Vasc Endovasc Surg. 2010;40:515-20.

49. Bhamidipaty V, Dean A, Yap SL, Firth J, Barron M, Allard B, et al. Second toe systolic pressure measurements are valid substitutes for first toe systolic pressure measurements in diabetic patients: a prospective study. Eur J Vasc Endovasc Surg. 2015;49:77-82.

50. Xu D, Zou L, Xing Y, Hou L, Wei Y, Zhang J, et al. Diagnostic value of ankle-brachial index in peripheral arterial disease: a meta-analysis. Can J Cardiol. 2012;29:492-8.

51. Young MJ, Every N, Boulton AJM. A comparison of the neurothesiometer and biothesiometer for measuring vibration perception in diabetic patients. Diabetes Res Clin Pract. 1993;20:129-31.
52. Armstrong DWJ, Tobin C, Matangi MF. The accuracy of the physical examination for the detection of lower extremity peripheral arterial disease. Can J Cardiol. 2010;26:e346-50.

53. O'Hare A, Johansen K. Lower-extremity peripheral arterial disease among patients with end-stage renal disease. J Am Soc Nephrol. 2001;12:2838-47.

54. Takahara M, Kaneto H, lida O, Katakami N, Matsuoka T-A, Ikeda M, et al. Association of diabetes and hemodialysis with ankle pressure and anklebrachial index in Japanese patients with critical limb ischemia. Diabetes Care. 2012;35:2000-4.

55. Reiber GE, Vileikyte L, Boyko EJ, del Aguila M, Smith DG, Lavery LA, et al. Causal pathways for incident lower-extremity ulcers in patients with diabetes from two settings. Diabetes Care. 1999;22:157-62.

56. Ledoux WR, Shofer JB, Smith DG, Sullivan K, Hayes SG, Assal M, et al. Relationship between foot type, foot deformity, and ulcer occurrence in the high-risk diabetic foot. J Rehabil Res Dev. 2005;42:665-71.

57. Garrow AP, Papageorgiou A, Silman AJ, Thomas E, Jayson MIV, Macfarlane GJ. The grading of hallux valgus - the Manchester scale. J Am Podiatr Med Assoc. 2001;91:74-8.

58. Menz HB, Munteanu SE. Radiographic validation of the Manchester scale for the classification of hallux valgus deformity. Rheumatology (Oxford). 2005:44:1061-6.

59. Lavery LA, Armstrong DG, Vela SA, Quebedeaux TL, Fleischli JG. Practical criteria for screening patients at high risk for diabetic foot ulceration. Arch Intern Med. 1998;158:157-62.

60. Hopson MM, McPoil TG, Cornwall MW. Motion of the first metatarsophalangeal joint. Reliability and validity of 4 measurement techniques. J Am Podiatr Med Assoc. 1995;85:198-204.

61. Veves A, Murray HJ, Young MJ, Boulton AJ. The risk of foot ulceration in diabetic patients with high foot pressure: a prospective study. Diabetologia. 1992;35:660-3

62. Pham H, Armstrong DG, Harvey C, Harkless LB, Giurini JM, Veves A. Screening techniques to identify people at high risk for diabetic foot ulceration: a prospective multicenter trial. Diabetes Care. 2000;23:606-11.

63. Kästenbauer T, Sauseng S, Sokol G, Auinger M, Irsigler K. A prospective study of predictors for foot ulceration in type 2 diabetes. J Am Podiatr Med Assoc. 2001;91:343-50.

64. Zammit GV, Menz HB, Munteanu SE. Reliability of the TekScan MatScan(R) system for the measurement of plantar forces and pressures during barefoot level walking in healthy adults. J Foot Ankle Res. 2010;3:11.

65. Barton CJ, Menz HB, Bonanno DR. Development and evaluation of a tool for the assessment of footwear characteristics. J Foot Ankle Res. 2009;2:10.

66. Jennings MB, Logan L, Alfieri DM, Ross CF, Goodwin S, Lesczczynski C. A comparative study of lactic acid $10 \%$ and ammonium lactate $12 \%$ lotion in the treatment of foot xerosis. J Am Podiatr Med Assoc. 2002;92:143-8.

67. Rogers RS, Callen J, Wehr R, Krochmal L. Comparative efficacy of $12 \%$ ammonium lactate lotion and $5 \%$ lactic acid lotion in the treatment of moderate to severe xerosis. J Am Acad Dermatol. 1989;21:714-6.

68. Jennings MB, Alfieri D, Ward K, Lesczczynski C. Comparison of salicylic acid and urea versus ammonium lactate for the treatment of foot xerosis. A randomized, double-blind, clinical study. J Am Podiatr Med Assoc. 1998;88:332-6

69. Frowen P, O'Donnell M, Burrow GJ, Lorimer DL. Neale's disorders of the foot. 8th ed. Edinburgh/New York: Churchill Livingstone/Elsevier; 2010.

70. Dyachenko P, Shustak A, Rozenman D. Hemodialysis-related pruritus and associated cutaneous manifestations. Int J Dermatol. 2006;45:664-7.

71. Khanna D, Singal A, Kalra OP. Comparison of cutaneous manifestations in chronic kidney disease with or without dialysis. Postgrad Med J. 2010;86:641-7.

72. Budisavljevic MN, Cheek D, Ploth DW. Calciphylaxis in chronic renal failure. J Am Soc Nephrol. 1996;7:978-82.

73. Oyibo SO, Jude EB, Tarawneh I, Nguyen HC, Harkless LB, Boulton AJM. A comparison of two diabetic foot ulcer classification systems: The Wagner and the University of Texas wound classification systems. Diabetes Care. 2001;24:84-8.

74. Rayman G, Krishnan ST, Baker NR, Wareham AM, Rayman A. Are we underestimating diabetes-related lower-extremity amputation rates? Results and benefits of the first prospective study. Diabetes Care. 2004;27:1892-6.

75. Campbell LV, Graham AR, Kidd RM, Molloy HF, O'Rourke SR, Colagiuri S. The lower limb in people with diabetes: position statement of the Australian Diabetes Society. Med J Aust. 2000;173:369-72.

76. Combe C, Jadoul M, Pisoni RL, Albert JM, Bragg-Gresham JL, Andreucci VE, et al. The burden of amputation among hemodialysis patients in the 
Dialysis Outcomes and Practice Patterns Study (DOPPS). Am J Kidney Dis 2009:54:680-92.

77. Otte J, van Netten JJ, Woittiez AJ. The association of chronic kidney disease and dialysis treatment with foot ulceration and major amputation. J Vasc Surg. 2015. doi:10.1016/j.jvs.2015.02.051.

78. Kulkarni N, Pierse N, Rushton L, Grigg J. Carbon in airway macrophages and lung function in children. N Engl J Med. 2006;355:21-30.

79. Bland JM, Altman DG. Measuring agreement in method comparison studies. Stat Methods Med Res. 1999;8:135-60.

80. Sim J, Wright CC. The kappa statistic in reliability studies: use, interpretation, and sample size requirements. Phys Ther. 2005:85:257-68.

81. Tooth LR, Ottenbacher KJ. The kappa statistic in rehabilitation research: an examination. Arch Phys Med Rehabil. 2004;85:1371-6.

82. Bernal Pedreño E, Salces Sáez E, Sambruno Giráldez A. Exploración del pie a los pacientes diabéticos de una unidad de hemodiálisis [Examination of the foot of diabetic patients in a haemodialysis unit]. Rev Soc Esp Enferm Nefrol. 2009:12:111-6.

83. García Viejo A. Enfermedad arterial periférica y pié diabético en pacientes en programa de hemodiálisis [Peripheral arterial disease and diabetic foot in patients on haemodialysis programme]. Enferm Nefrol. 2012;15:255-64.

84. Lancho Casares JM, Juan Larma T, de Vega JC, Nieto Guerrero M, Acedo Agúndez J. Patient on dialysis programme and peripheral arteriopathy [Paciente en programa de diálisis y arteriopatía periférica]. Rev Soc Esp Enferm Nefrol. 2008;11:82-7.

85. Mark P, McNally M, Jones GC. Deficiencies in foot care of diabetic patients on renal replacement therapy. Pract Diab Int. 2003;20:294-6.

86. Mclntyre I, Boughen C, Trepman E, Embil JM. Foot and ankle problems of Aboriginal and non-Aboriginal diabetic patients with end-stage renal disease. Foot Ankle Int. 2007;28:674-86.

87. Yasuhara $H$, Naka $S$, Yanagie $H$, Nagawa $H$. Influence of diabetes on persistent nonhealing ischemic foot ulcer in end-stage renal disease. World J Surg. 2002;26:1360-4.

88. Schleiffer T, Hölken H, Brass H. Morbidity in 565 type 2 diabetic patients according to stage of nephropathy. J Diabetes Complications. 1998;12:103-9.

89. Freeman A, May K, Frescos N, Wraight PR. Frequency of risk factors for foot ulceration in individuals with chronic kidney disease. Intern Med J. 2008;38:314-20

90. Wolf G, Müller N, Busch M, Eidner G, Kloos C, Hunger-Battefeld W, et al. Diabetic foot syndrome and renal function in type 1 and 2 diabetes mellitus show close association. Nephrol Dial Transplant. 2009;24:1896-901.

91. Armstrong DG. The 10-g monofilament: the diagnostic divining rod for the diabetic foot? Diabetes Care. 2000;23:887.

92. Bonham PA. Get the LEAD out: noninvasive assessment for lower extremity arterial disease using ankle brachial index and toe brachial index measurements. J Wound Ostomy Continence Nurs. 2006;33:30-41.

93. Romanos MT, Raspovic A, Perrin BM. The reliability of toe systolic pressure and the toe brachial index in patients with diabetes. J Foot Ankle Res. 2010. doi: 10.1186/1757-1146-3-31.

94. Bus SA, Lange A. A comparison of the 1-step, 2-step, and 3-step protocols for obtaining barefoot plantar pressure data in the diabetic neuropathic foot. Clin Biomech. 2005;20:892-9.

95. Malhotra S, Bello E, Kominsky S. Diabetic foot ulcerations: biomechanics, Charcot foot, and total contact cast. Semin Vasc Surg. 2012;25:66-9. 